\title{
Deprotonation of Water/Hydroxo Ligands in Clusters Mimicking the Water Oxidizing Complex of PSII and Its Effect on the Vibrational Frequencies of Ligated Carboxylate Groups
}

\author{
Wooi Yee Chuah, ${ }^{* \dagger}$ Rob Stranger, ${ }^{* \dagger}$ Ron J. Pace, ${ }^{* \dagger}$ Elmars Krausz, ${ }^{* \dagger}$ and Terry J. Frankcombe ${ }^{*, \dagger, *}$ \\ ${ }^{\dagger}$ Research School of Chemistry, Australian National University, Canberra, Australian Capital Territory 2601, Australia \\ ${ }^{\ddagger}$ School of Physical, Environmental and Mathematical Sciences, University of New South Wales, Canberra, Australian Capital \\ Territory 2600, Australia
}

Supporting Information

ABSTRACT: The IR absorptions of several first-shell carboxylate ligands of the water oxidizing complex (WOC) have been experimentally shown to be unaffected by oxidation state changes in the WOC during its catalytic cycle. Several model clusters that mimic the $\mathrm{Mn}_{4} \mathrm{O}_{5} \mathrm{Ca}$ core of the WOC in the $S_{1}$ state, with electronic configurations that correspond to both the so-called "high" and "low" oxidation paradigms, were investigated. Deprotonation at W2, W1, or O3 sites was found to strongly reduce carboxylate ligand frequency shifts on oxidation of the metal cluster. The frequency shifts were smallest in neutrally charged clusters where the initial mean Mn oxidation state was +3 , with W2 as an hydroxide and O5 a water. Deprotonation also reduced and balanced the oxidation energy of all clusters in successive oxidations.

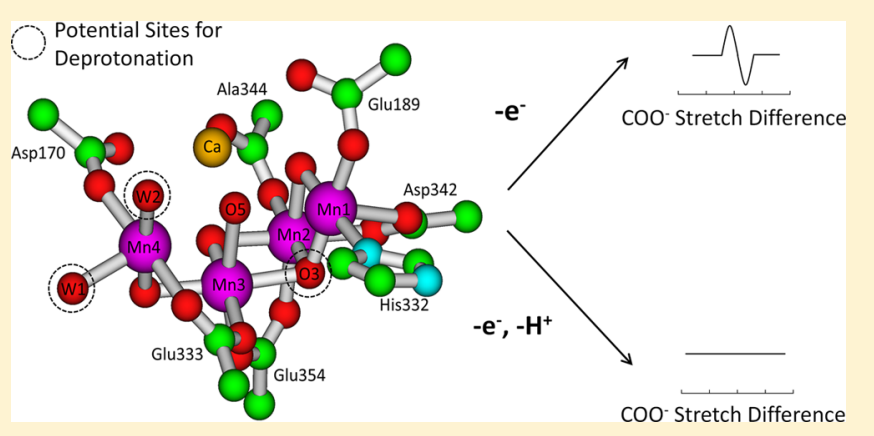

\section{INTRODUCTION}

Photosystem II (PSII) is a protein supercomplex found in all organisms that perform oxygenic photosynthesis. In PSII, light energy catalyzes the oxidation of water into protons and oxygen, which in turn enables the production of ATP and $\mathrm{NADPH}$ in the photosynthetic process. ${ }^{1}$ The water oxidation reaction occurs at a catalytic site known as the water oxidizing complex (WOC), which is a metallorganic cluster containing a $\mathrm{Mn}_{4} \mathrm{O}_{5} \mathrm{Ca}$ core. The WOC cycles through four metastable intermediate states (of increasing mean oxidation level), called $S$-states, labeled $S_{i}(i=0-3)$, and one transient state, $S_{4}$. Each $\mathrm{S}$-state is progressively generated by a single electron donation from the WOC, to the photo-oxidized reaction center, P680, via the intermediate electron transfer moiety, tyrosine $\mathrm{Z}\left(\mathrm{Y}_{\mathrm{Z}}\right)$. Oxygen is released in a concerted reaction on the $S_{4}$ to $S_{0}$ transition, while the dark stable state of the cluster is $S_{1}$. The WOC has been investigated with a number of spectroscopic methods, such as extended X-ray absorption fine structure (EXAFS), X-ray diffraction (XRD), electron paramagnetic resonance (EPR), and Fourier transform infrared spectroscopy (FTIR) to name but a few, but the mechanism of water oxidation at the WOC is still a contentious topic, due to the wide range of possible interpretations of the spectroscopic data. For instance, the interpretation of X-ray spectroscopic data from measurements of the $S_{3}$ state is still being vigorously debated, with some researchers suggesting Mn-centered oxidation in the $S_{2}$ to $S_{3}$ transition, while others favor ligandcentered oxidation. $^{2-4}$ However, it is well-established that the
$S_{0}$ and $S_{2}$ states have odd total Mn electron spin, while $S_{1}$ and $\mathrm{S}_{3}$ are even spin. ${ }^{5-7}$

In 2011, Shen and co-workers obtained the first XRD structure of PSII capable of resolving the precise structure and ligation of the WOC, with a resolution of $1.9 \AA$. This structure indicated that the WOC has six direct "first-shell" carboxylate ligands, which are D1-Asp170, D1-Glu333, D1-Asp342, D1Ala344, D1-Glu189, and CP43-Glu354. ${ }^{8,9}$ The most recent 1.95 $\AA$ XRD structure, obtained using femtosecond pulses so as to avoid radiation damage, was largely unchanged from the $1.9 \AA$ structure. ${ }^{10}$ These first-shell ligands have been extensively studied using site-directed mutagenesis in combination with FTIR difference spectroscopy. Puzzlingly, mutations to Asp170, Glu333, Asp342, and Glu189 produced no significant changes in any of the $S_{n+1}$-minus- $S_{n}$ FTIR difference spectra within the midfrequency region $\left(1000-2000 \mathrm{~cm}^{-1}\right)$, while the Glu354Q mutant produces a very different $S_{2} / S_{1}$ spectrum from the wildtype. $^{11}$ Mutations to D1-Asp170 and D1-Glu189 do, however, cause pronounced differences in the low-frequency region that correspond to metal-metal and metal-oxo vibrations. ${ }^{12,13}$

In a previous study of model compounds, we found that that the deprotonation of terminal water/hydroxyl ligands during oxidation of a Mn center reduces frequency changes in the

Received: October 12, 2015

Revised: December 13, 2015

Published: January 4, 2016 
stretching modes of ligated carboxylates, and also results in a relatively constant oxidation energy (see eq 1 ) for the $\mathrm{Mn}$ (II)/ $\mathrm{Mn}(\mathrm{III})$ and $\mathrm{Mn}(\mathrm{III}) / \mathrm{Mn}(\mathrm{IV})$ redox pairs. ${ }^{14} \mathrm{~A}$ recent study by Terrett et al. on a binuclear $\mathrm{Mn}-\mathrm{Ca}$ complex analogous to the Asp170 region of the WOC further confirms those findings. ${ }^{15}$ Studies on synthetic carboxylate-bridged Mn dimer complexes by Eilers et al. also demonstrated that carboxylate stretching frequencies remain unchanged when deuterated water ligands are deprotonated. ${ }^{16}$

In this study, we examine model clusters based on the $1.9 \AA$ XRD structure of the WOC (see Figure 1), to assess whether

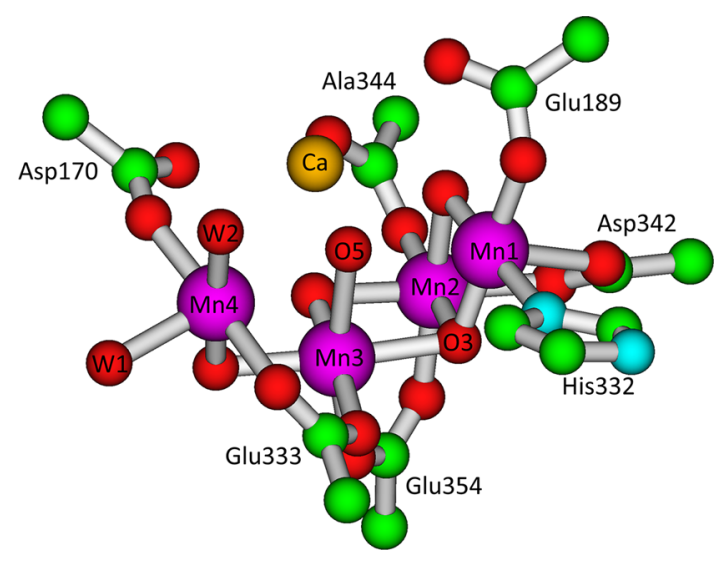

Figure 1. Geometry of the $\mathrm{Mn}_{4} \mathrm{O}_{5} \mathrm{Ca}$ cluster in the $1.9 \AA \mathrm{XRD}$ structure of the WOC. ${ }^{9}$ The atoms are colored as follows: $\mathrm{Mn}$, purple; $\mathrm{Ca}$, yellow; C, green; $\mathrm{O}$, red; $\mathrm{N}$, light blue. The carboxylate ligands are shown as acetates, while all protons, and water molecules that do not directly bind to manganese centers, are omitted for clarity.

the results of our previous study can be scaled to WOC-like clusters. Scaling to WOC-like clusters is made more complicated by the likelihood of resonances between multiple carboxylate and water bending vibrations, and uncertainty in the hydrogenation of the heavy atoms visible to XRD. We suggest that the deprotonation of water/hydroxyl ligands may be responsible for the absence of oxidation-induced difference features in the carboxylate modes of the WOC's first-shell carboxylate ligands. Our results also show that the frequency shifts that still remain following oxidation with deprotonation are not independent of model geometry or electronic state; the lack of observable experimental FTIR shifts then implies that the effective suppression of oxidation-driven carboxylate frequency shifts through deprotonation may be a requirement for accurate models of the WOC.

\section{METHODS}

The $\mathrm{Mn}_{4} \mathrm{O}_{5} \mathrm{Ca}$ clusters were constructed on the basis of the 1.9 $\AA$ XRD structure by Umena et al., ${ }^{9}$ with the first-shell carboxylate ligands of the WOC being modeled by formate ligands. Only the core metal centers and the direct ligands to the Mn centers were included, with each model encompassing $\sim 50$ atoms. The initial oxidation states of the $\mathrm{Mn}$ ions within the clusters were selected to give an average of +3 or +3.5 , to investigate both oxidation state schemes proposed for the $S_{1}$ state of the WOC. ${ }^{17-27}$ While the lower oxidation scheme has been argued against by Cox and co-workers, ${ }^{28}$ it is quantitatively consistent with all published high-resolution crystal structures of the $S_{1}$ state, including the most recent at $1.95 \AA^{25}$ For a further discussion on the validity of either oxidation state scheme, please refer to refs $19,25,26$, and 28-31. The nomenclature used in this study to refer to particular manganese and oxygen sites is the same as that used by Umena et al. in describing the $1.9 \AA \mathrm{XRD}$ structure of the WOC, and is illustrated in Figure 1.

Geometry optimization and harmonic vibrational frequency calculations were performed in the gas phase, using the M06L/ 6-31G $(\mathrm{d}, \mathrm{p})$ method in Gaussian09. ${ }^{32}$ All clusters were assigned a high-spin state to ease convergence, and the oxidation states were controlled by specifying the charge and electronic spin multiplicity of the cluster in question. The converged oxidation state of the metal centers and that of ligands was obtained from the calculated Mulliken spin density. We probed all oxidation pathways from the initial dark stable " $\mathrm{S}_{1}$ " state of the cluster for up to three consecutive oxidations, with and without deprotonation (for up to two consecutive deprotonations). Oxidations that result in significant distortions of the geometry were considered unrepresentative of the WOC, and thus were excluded from the results.

The use of formate ligands and the M06L/6-31G(d,p) method were justified by results obtained from our previous study; increasing ligand chain length had very little effect on the response of carboxylate frequencies to oxidation, and $\mathrm{M} 06 \mathrm{~L}$ produced results similar to those obtained using CCSD, in terms of geometries, frequency shifts, and oxidation energies. Use of the $6-31 G(d, p)$ basis set produced results similar to the larger SDD $(\mathrm{Ca}, \mathrm{Mn})+6-31 \mathrm{G}(\mathrm{d}, \mathrm{p})(\mathrm{C}, \mathrm{O}, \mathrm{N}, \mathrm{H})$ mixed basis set regardless of the method employed. ${ }^{14}$ We also note that $\mathrm{M} 06 \mathrm{~L}$ has a harmonic frequency scaling factor of $\sim 0.99$ for most basis sets. $^{33}$

The carboxylate symmetric and asymmetric stretching modes were identified by inspection. The formate protons were deuterated to prevent nonphysical coupling of $\mathrm{C}-\mathrm{H}$ wag vibrations with the carboxylate symmetric stretches.

The oxidation energy for an oxidation step is given by

$$
E_{\text {oxidation }}=E_{\text {oxidized }}+n E_{\mathrm{H}}-E_{\text {initial }}
$$

where $E_{\text {Oxidised }}, E_{\mathrm{H}}$, and $E_{\text {Initial }}$ are the energies calculated for the oxidized cluster, the hydrogen atom, and the cluster before oxidization, respectively, and $n$ is the number of protons removed $(n=0$ or 1$)$. Please note that the oxidation energies are not directly comparable with the physiological system and are meant for relative comparisons within this study only.

Exploratory calculations on one of the clusters used in the current work confirmed that the SDD+6-31G(d,p) mixed basis set produced results nearly identical to $6-31 \mathrm{G}(\mathrm{d}, \mathrm{p})$, while setting the same cluster to the low-spin state had a negligible effect on the oxidation energies and the frequency differences caused by oxidation. $\omega$ B97XD, PBE0-D3, B3LYP-D3, and M11L (using the SDD + 6-31G(d,p) basis set) all produced very similar relative energies and frequency shifts to M06L, for this cluster. These results are provided in the Supporting Information.

\section{RESULTS}

The six clusters selected in this study to model a range of initial protonations at $\mathrm{O} 3, \mathrm{O} 5$, and $\mathrm{W} 2$ in different metal oxidation states (as proposed by various authors ${ }^{21,27,34}$ ) are shown in Figure 2. The protonation and electronic configuration of the clusters in their initial state are described in Table 1; calculations on $\mathbf{E}$ and $\mathbf{F}$ did not converge when their mean oxidations were set to +3 (with an overall charge of -2 ). Note that clusters $\mathbf{A}$ through $\mathbf{D}$ possess a mean oxidation of +3.5 
A

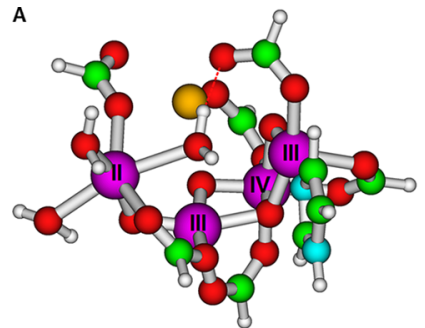

C

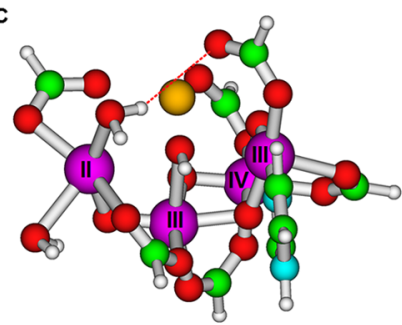

E

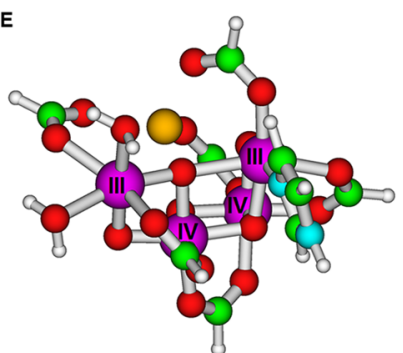

B

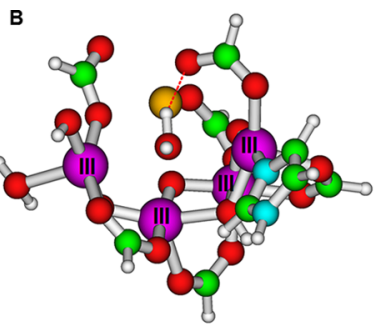

D
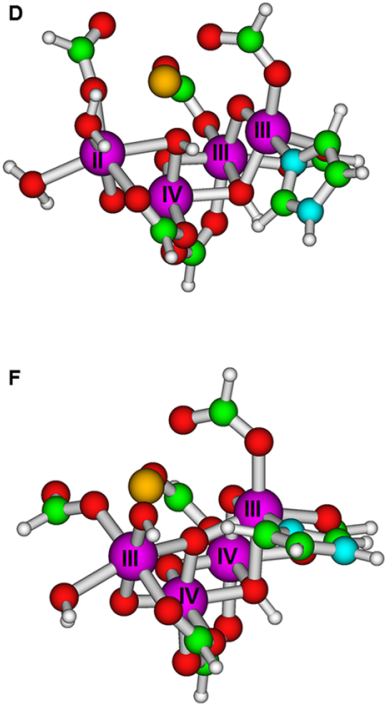

Figure 2. Optimized structures of the model $\mathrm{Mn}_{4} \mathrm{O}_{5} \mathrm{Ca}$ clusters investigated in this study, in their initial state. These clusters were obtained by performing geometry optimizations on the $\mathrm{Mn}_{4} \mathrm{O}_{5} \mathrm{Ca}$ core of the $1.9 \AA \mathrm{XRD}$ structure, with varied protonation and oxidation states. The atoms are colored as follows: $\mathrm{Mn}$, purple; $\mathrm{Ca}$, yellow; $\mathrm{C}$, green; $\mathrm{O}$, red; $\mathrm{N}$, light blue; $\mathrm{H}$, gray. The oxidation state of each $\mathrm{Mn}$ center is labeled in roman numerals. See Figure 1 for the corresponding XRD structure.

Table 1. Oxidation State, Formal Charge, Multiplicity, and the Identity of O5, W2, and $\mathrm{O} 3$ in Each of the Clusters Investigated in This Study, in Their Initial State

$\begin{array}{ccccccc}\text { cluster } & \begin{array}{c}\text { lowest ox. } \\ \text { state }\end{array} & \text { charge } & \begin{array}{c}\text { multiplicity } \\ (2 \mathrm{~S}+1)\end{array} & \mathrm{O} 5 & \mathrm{~W} 2 & \mathrm{O} 3 \\ \text { A } & 3,4,3,2 & 0 & 17 & \mathrm{H}_{2} \mathrm{O} & \mathrm{H}_{2} \mathrm{O} & \mathrm{O}^{2-} \\ \text { B } & 3,3,3,3 & 0 & 17 & \mathrm{H}_{2} \mathrm{O} & \mathrm{OH}^{-} & \mathrm{OH}^{-} \\ \text {C } & 3,4,3,2 & -1 & 17 & \mathrm{OH}^{-} & \mathrm{H}_{2} \mathrm{O} & \mathrm{O}^{2-} \\ \text { D } & 3,3,4,2 & 0 & 17 & \mathrm{OH}^{-} & \mathrm{H}_{2} \mathrm{O} & \mathrm{OH}^{-} \\ \text {E } & 3,4,4,3 & 0 & 15 & \mathrm{O}^{2-} & \mathrm{H}_{2} \mathrm{O} & \mathrm{O}^{2-} \\ \text { F } & 3,4,4,3 & 0 & 15 & \mathrm{O}^{2-} & \mathrm{OH}^{-} & \mathrm{OH}^{-}\end{array}$

after two oxidations, albeit with an overall charge of +2 if directly oxidized. All Mn Mulliken spin densities can be found in the Supporting Information.

These clusters are reduced representations of the $S_{1}$ state of the WOC; see Figure 1 for the comparable $1.9 \AA \mathrm{XRD}$ structure. In Figure 2, these are arranged according to the protonation state of $\mathrm{O} 5$ : $\mathrm{O} 5$ as $\mathrm{H}_{2} \mathrm{O}$ in the first row, $\mathrm{OH}^{-}$in the second row, and $\mathrm{O}^{2-}$ in the third row. Clusters $\mathbf{A}$ and $\mathbf{E}$ are tautomers to $\mathbf{B}$ and $\mathbf{F}$, respectively, having a proton from W2 transferred to O3. This follows a suggestion by Gatt et al., ${ }^{21}$ that a proton transfer involving W2 and O3 could rationalize the difference between the "short" $\mathrm{Mn}-\mathrm{Mn}$ distances seen in EXAFS $(\sim 2.7 \AA)$ and those seen in XRD $(\sim 2.8-2.9 \AA)$, both

for the nominal $\mathbf{S}_{1}$ state. $\mathbf{D}$ is not a tautomer of $\mathbf{C}$, but is closely related as it has almost the same protonation pattern as $\mathrm{C}$, except for an additional proton at O3. Setting W2 as $\mathrm{OH}$ in D caused the geometry to distort strongly. We found that $\mathbf{A}, \mathbf{B}$, and $\mathrm{C}$ have relatively long $\mathrm{Mn}-\mathrm{O} 5$ distances $(\sim 2.4-2.5 \AA)$, similar to those observed in the $1.9 \AA \mathrm{XRD}$ structure, which are largely retained in the latest $1.95 \AA \mathrm{XRD}$ structure. ${ }^{8-10}$

The models here resemble some of the $S_{1}$ state models proposed by various authors, although it must be noted that these were never intended to represent fully mechanistic models of the WOC. $\mathbf{A}$ and $\mathbf{B}$ are similar to the models presented by Gatt et al., while $\mathbf{C}$ and $\mathbf{D}$ are reminiscent of the models proposed by Petrie and Shoji, with a hydroxide in the O5 position. ${ }^{25,35}$ Clusters $\mathbf{E}$ and $\mathbf{F}$, which have an average $\mathrm{Mn}$ oxidation of +3.5 and a fully deprotonated O5 oxo-bridge, resemble the models of Amin, Pantazis, and Siegbahn. ${ }^{23,36,37} \mathbf{F}$ in particular has a protonation pattern that is similar to the models found most compatible with EPR/ENDOR and EXAFS spectroscopic properties by Ames and co-workers, as W2 was also modeled as a hydroxide ligand. ${ }^{19}$

Nevertheless, the goal of this study is to evaluate the effectiveness of deprotonation in suppressing carboxylate frequency shifts, and how they depend on the geometry and electronic state of the model clusters. It is not to evaluate the accuracy of any of the aforementioned models in the literature, as we make no investigation of water oxidation with these small models.

The relative energy levels of each cluster on oxidation, both direct and with deprotonation, are shown in Figure 3. The manganese oxidation states are also indicated. In all clusters except $\mathbf{C}$, which is negatively charged in its lowest oxidation state, deprotonation lowers the oxidation energy of the cluster. Deprotonation also maintains the oxidation energies of successive oxidations to be within $1 \mathrm{eV}$ of each other, whereas oxidizing the clusters without deprotonation causes rapid increases in the oxidation energy. However, we note that the oxidation energies associated with oxidation with deprotonation are $\sim 3 \mathrm{eV}$, which is too high compared to the likely potential of $\mathrm{P}^{6} 80^{+}$. $38-40$

Figures 4 and 5 summarize the gross effect of deprotonation on carboxylate frequency shifts. When the mean Mn oxidation is +3 (Figure 4), the deprotonation of W1 and W2 significantly suppresses frequency shifts in all clusters compared to oxidation without deprotonation, except the negatively charged $\mathbf{C}$ whose average shift does not appear to vary, regardless of deprotonation. O3 deprotonation significantly suppresses shifts for $\mathbf{B}$, but is less effective for $\mathbf{D}$, whose shifts with $\mathrm{O} 3$ deprotonation are twice those recorded with W1 or W2 deprotonation. O5 deprotonation with oxidation, however, causes large shifts comparable to those caused by direct oxidation.

When the mean Mn oxidation level is +3.5 (Figure 5), the deprotonation of W1 suppresses oxidation-related frequency shifts, with the exception of E. O3 deprotonation, on the other hand, was generally ineffective, except for the neutrally charged F. At this level of mean oxidation, oxidation with W2 deprotonation consistently resulted in $\mathrm{Mn} 1$ being oxidized instead of Mn4 (which W2 ligates), and resulted in relatively large frequency shifts. Note that this figure includes data from clusters $\mathbf{E}$ and $\mathbf{F}$ which have an initial mean $\mathrm{Mn}$ oxidation of +3.5 , as well as the doubly oxidized clusters A-D.

Tables 2-5 describe the frequency shifts associated with manganese-centered oxidation, from $\mathrm{Mn} 1$ to $\mathrm{Mn} 4$, respectively. 

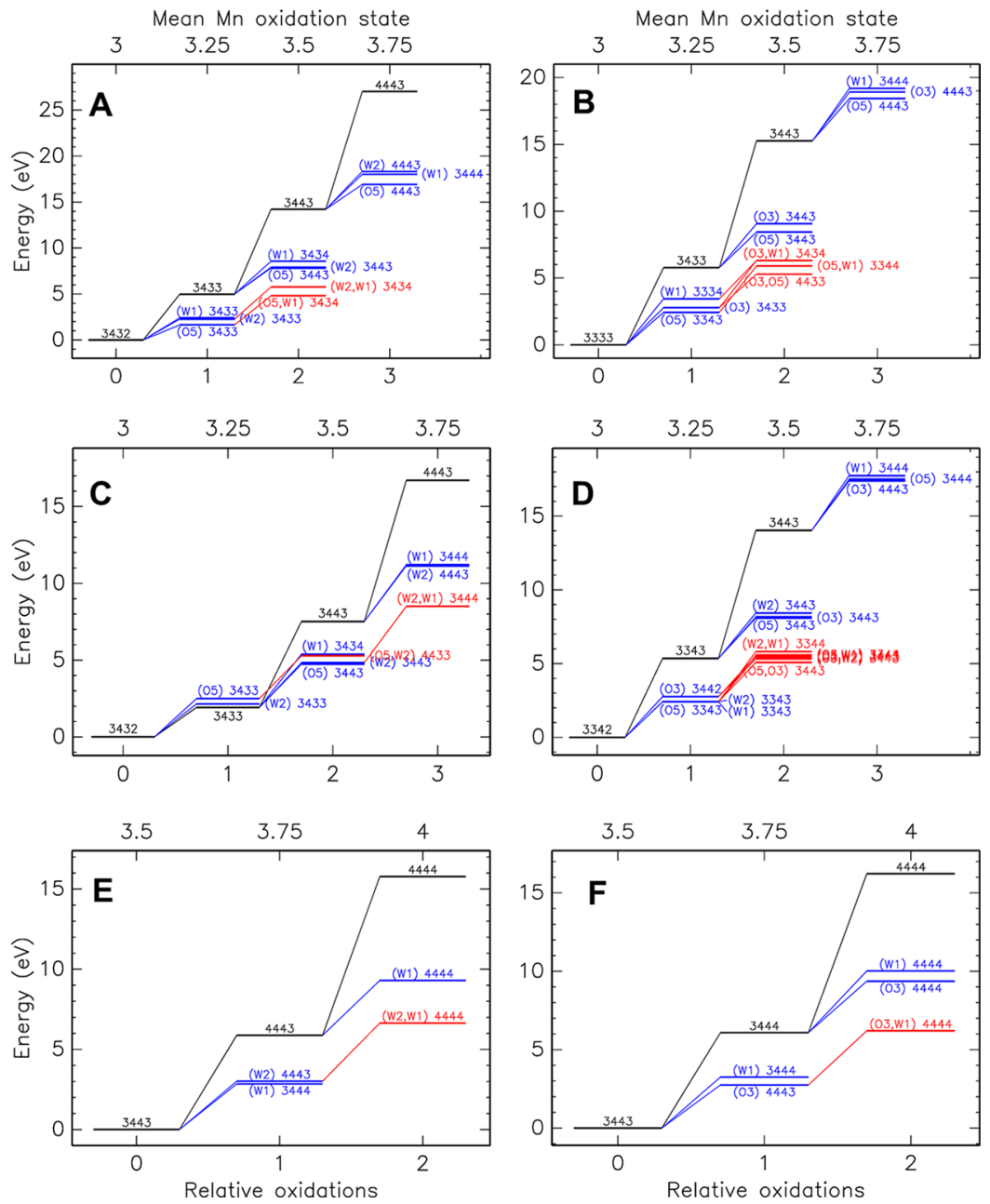

Figure 3. Oxidations undertaken by each cluster, shown with the Mn oxidation states, deprotonated species, and relative energies. The initial mean Mn oxidation state is +3 for clusters $\mathbf{A}-\mathbf{D}$, and +3.5 for clusters $\mathbf{E}$ and $\mathbf{F}$. The lower $x$-axis gives the number of relative oxidations, while the upper $x$ axis gives the mean $\mathrm{Mn}$ oxidation. The oxidation state is given in the order of $\mathrm{Mn} 1-\mathrm{Mn} 4$, while the types of oxidation are differentiated by the color of the lines. Single and repeated oxidation with deprotonation are indicated by blue and red lines, respectively, while direct oxidations are indicated by black lines. The species deprotonated in each step is shown in brackets, in the order in which the deprotonations were undertaken.

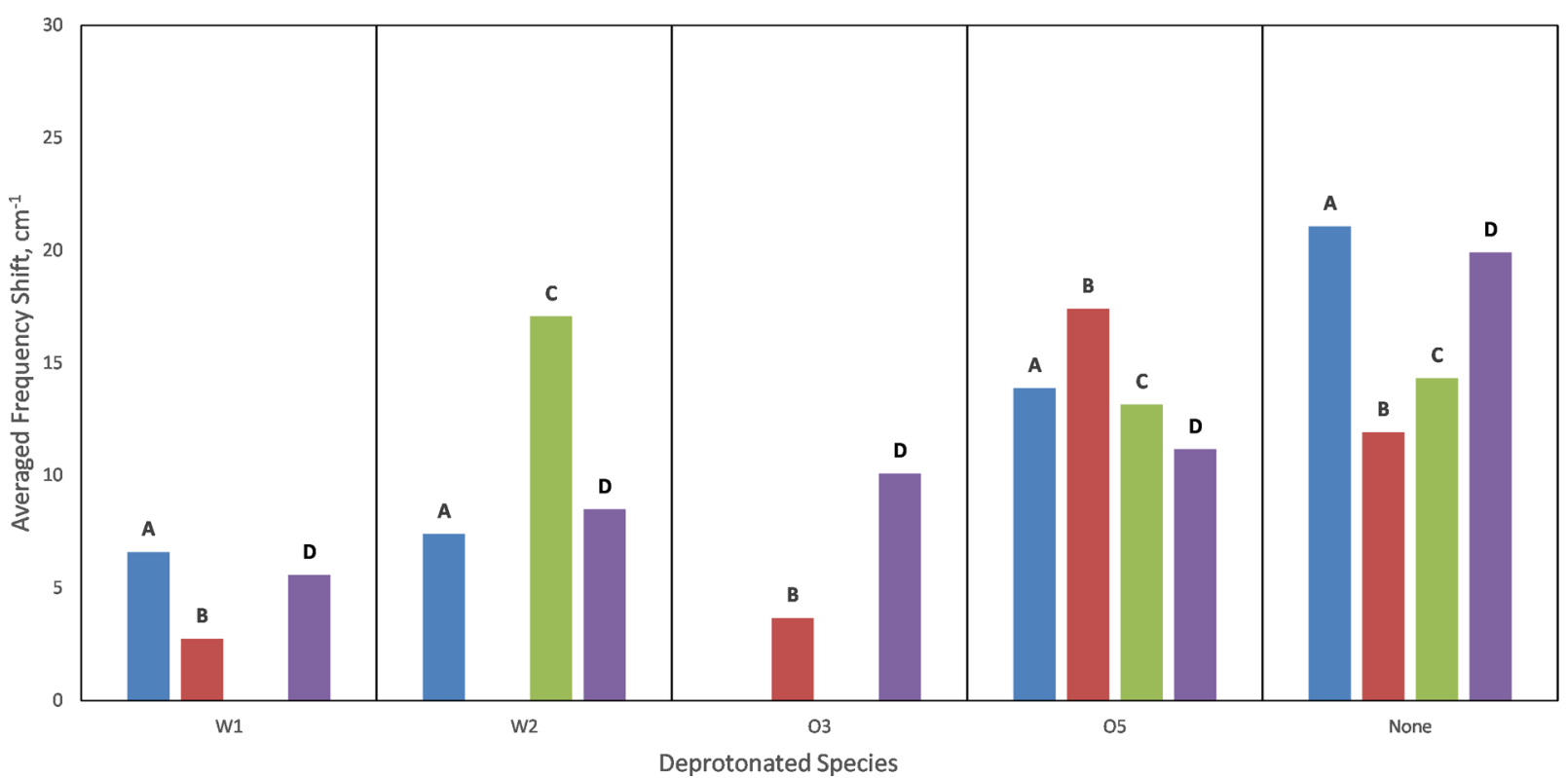

Figure 4. Average frequency shifts versus the deprotonated species, for all clusters with an initial mean Mn oxidation of +3 . 


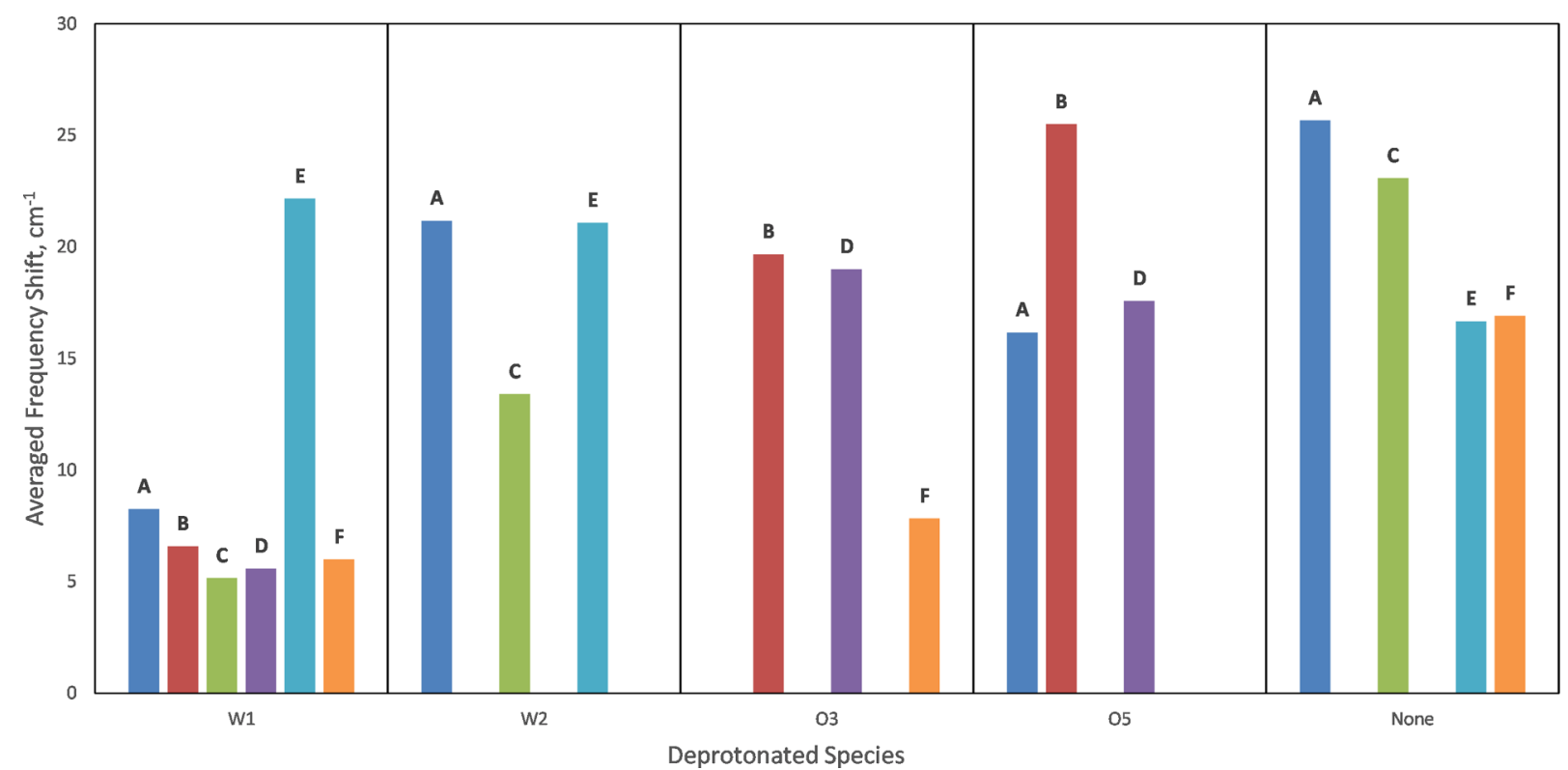

Figure 5. Average frequency shifts versus the deprotonated species, for all clusters with an initial mean Mn oxidation of +3.5 .

Table 2. Frequency Changes Associated with Oxidation of Mn1

\begin{tabular}{|c|c|c|c|c|c|c|c|c|c|c|c|c|c|c|c|c|}
\hline & \multirow[b]{2}{*}{$\begin{array}{c}\text { charge } \\
(\mathrm{i} / \mathrm{f})\end{array}$} & \multirow[b]{2}{*}{$\begin{array}{l}\text { final ox. } \\
\text { state }\end{array}$} & \multirow[b]{2}{*}{$\begin{array}{c}\text { final mult } \\
(2 S+1)\end{array}$} & \multirow[b]{2}{*}{$\begin{array}{l}\text { deprot } \\
\text { species }\end{array}$} & \multicolumn{2}{|c|}{ Asp170 } & \multicolumn{2}{|c|}{ Glu354 } & \multicolumn{2}{|c|}{ Glu189 } & \multicolumn{2}{|c|}{ Glu333 } & \multicolumn{2}{|c|}{ Asp342 } & \multicolumn{2}{|c|}{ Ala344 } \\
\hline & & & & & sym & asym & sym & asym & sym & asym & sym & asym & sym & asym & sym & asym \\
\hline \multirow[t]{3}{*}{ A } & $+2 /+3$ & $4,4,4,3$ & 14 & & -26 & +3 & -29 & -28 & -29 & -57 & -3 & -21 & -68 & +4 & -37 & -3 \\
\hline & $+2 /+2$ & $4,4,4,3$ & 14 & W2 & -32 & -10 & +3 & -34 & -32 & -36 & +5 & +5 & -58 & +25 & -13 & +1 \\
\hline & $+2 /+2$ & $4,4,4,3$ & 14 & O5 & -22 & +1 & +8 & -51 & -31 & +17 & -1 & +10 & -31 & +8 & -12 & +2 \\
\hline \multirow[t]{3}{*}{ B } & $0 / 0$ & $4,4,3,3$ & 15 & $\mathrm{O} 3, \mathrm{O} 5$ & -10 & +1 & 0 & -5 & -53 & +67 & +6 & 0 & -22 & -8 & -27 & -7 \\
\hline & $+2 /+2$ & $4,4,4,3$ & 14 & $\mathrm{O} 3$ & -12 & -3 & -13 & -17 & -31 & -49 & +6 & +1 & -58 & +28 & +12 & -6 \\
\hline & $+2 /+2$ & $4,4,4,3$ & 14 & OS & $\begin{array}{l}-8 \\
-13\end{array}$ & 0 & +4 & -47 & $\begin{array}{l}-96 \\
-101\end{array}$ & +60 & 0 & +7 & -39 & +3 & -29 & +8 \\
\hline \multirow[t]{3}{*}{$\mathrm{C}$} & $-1 /-1$ & $4,4,3,3$ & 15 & O5, W2 & +10 & -5 & +7 & -15 & -16 & -9 & +2 & +7 & -8 & -19 & -7 & -2 \\
\hline & $+1 /+1$ & $4,4,4,3$ & 14 & W2 & +19 & +1 & +2 & -20 & -36 & 0 & +6 & -6 & -34 & -22 & -13 & -2 \\
\hline & $+1 /+2$ & $4,4,4,3$ & 14 & & -25 & -5 & -17 & -31 & -49 & -6 & -13 & -20 & -38 & -35 & -30 & -8 \\
\hline D & $+2 /+2$ & $4,4,4,3$ & 14 & $\mathrm{O} 3$ & -10 & +19 & -25 & +3 & -13 & -11 & -9 & +8 & -43 & -30 & +18 & -39 \\
\hline \multirow[t]{2}{*}{$\mathrm{E}$} & $0 /+1$ & $4,4,4,3$ & 14 & & -24 & -3 & -5 & -15 & -21 & -12 & +1 & -20 & -4 & -68 & -25 & -2 \\
\hline & $0 / 0$ & $4,4,4,3$ & 14 & W2 & -57 & -48 & -4 & +2 & -22 & +20 & -4 & -18 & +4 & -51 & -21 & +2 \\
\hline \multirow[t]{4}{*}{ F } & $0 / 0$ & $4,4,4,3$ & 14 & $\mathrm{O} 3$ & -8 & +2 & +4 & -3 & -37 & +6 & -3 & -2 & -3 & 0 & +23 & -3 \\
\hline & $+1 /+2$ & $4,4,4,4$ & 13 & & -25 & -2 & -14 & -34 & -90 & +23 & -7 & -24 & -50 & -26 & -28 & -14 \\
\hline & $+1 /+1$ & $4,4,4,4$ & 13 & W1 & +2 & -11 & -9 & -15 & -64 & +26 & +9 & +2 & -25 & -16 & -12 & -10 \\
\hline & $+1 /+1$ & $4,4,4,4$ & 13 & $\mathrm{O} 3$ & -6 & -4 & -4 & +1 & -31 & +14 & -4 & +9 & -34 & -7 & +23 & -21 \\
\hline
\end{tabular}

Table 3. Frequency Changes Associated with Oxidation of Mn2

\begin{tabular}{|c|c|c|c|c|c|c|c|c|c|c|c|c|c|c|c|c|}
\hline & \multirow[b]{2}{*}{$\begin{array}{c}\text { charge } \\
(\mathrm{i} / \mathrm{f})\end{array}$} & \multirow[b]{2}{*}{$\begin{array}{l}\text { final ox. } \\
\text { state }\end{array}$} & \multirow[b]{2}{*}{$\begin{array}{l}\text { final mult } \\
(2 S+1)\end{array}$} & \multirow[b]{2}{*}{$\begin{array}{l}\text { deprot } \\
\text { species }\end{array}$} & \multicolumn{2}{|c|}{ Asp 170} & \multicolumn{2}{|c|}{ Glu354 } & \multicolumn{2}{|c|}{ Glu189 } & \multicolumn{2}{|c|}{ Glu333 } & \multicolumn{2}{|c|}{ Asp342 } & \multicolumn{2}{|c|}{ Ala344 } \\
\hline & & & & & sym & asym & sym & asym & sym & asym & sym & asym & sym & asym & sym & asym \\
\hline \multirow[t]{3}{*}{ B } & $0 /+1$ & $3,4,3,3$ & 16 & & -5 & +5 & +3 & -30 & -11 & -4 & -2 & -10 & +1 & -17 & -51 & +4 \\
\hline & $0 / 0$ & $3,4,3,3$ & 16 & O3 & -2 & -2 & -12 & -1 & -1 & +1 & -4 & -5 & -4 & 0 & -12 & 0 \\
\hline & $0 / 0$ & $3,4,3,4$ & 15 & $\mathrm{~W} 1, \mathrm{O} 3$ & -1 & -3 & -12 & -14 & 0 & +9 & -2 & -6 & -3 & -1 & -10 & +3 \\
\hline \multirow[t]{8}{*}{ D } & $0 / 0$ & $3,4,4,2$ & 16 & $\mathrm{O} 3$ & +6 & -12 & +5 & +7 & -2 & -20 & -1 & -2 & -4 & +2 & -28 & +32 \\
\hline & $0 / 0$ & $3,4,4,3$ & 15 & O5, w2 & -24 & -32 & +1 & -9 & -3 & +28 & +7 & -17 & -7 & -11 & -50 & +29 \\
\hline & $0 / 0$ & $3,4,4,3$ & 15 & $\mathrm{O} 5, \mathrm{O} 3$ & +2 & -32 & +6 & -9 & -4 & +28 & -1 & -17 & -1 & -11 & -28 & +29 \\
\hline & $0 / 0$ & $3,4,4,3$ & 15 & $\mathrm{~W} 2, \mathrm{O} 3$ & +6 & -5 & +3 & +1 & -1 & -3 & -2 & -4 & -4 & -1 & -28 & +9 \\
\hline & $+1 /+2$ & $3,4,4,3$ & 15 & & -15 & -20 & +17 & -41 & -37 & +5 & +1 & -33 & +2 & +16 & -87 & +52 \\
\hline & $+1 /+1$ & $3,4,4,3$ & 15 & $\mathrm{O} 3$ & +10 & -3 & +13 & -23 & -3 & -2 & +1 & -3 & -4 & +21 & -38 & +21 \\
\hline & $+1 /+1$ & $3,4,4,3$ & 15 & W2 & +11 & -18 & +17 & -39 & -9 & -6 & +4 & +3 & -9 & +5 & -73 & +51 \\
\hline & $+1 /+1$ & $3,4,4,3$ & 15 & O5 & -1 & -29 & +12 & -54 & +22 & -46 & +5 & -11 & -19 & -6 & -58 & +42 \\
\hline
\end{tabular}


Table 4. Frequency Changes Associated with Oxidation of Mn3

\begin{tabular}{|c|c|c|c|c|c|c|c|c|c|c|c|c|c|c|c|c|}
\hline & \multirow[b]{2}{*}{$\begin{array}{c}\text { charge } \\
(\mathrm{i} / \mathrm{f})\end{array}$} & \multirow[b]{2}{*}{$\begin{array}{l}\text { final ox. } \\
\text { state }\end{array}$} & \multirow[b]{2}{*}{$\underset{1)}{\operatorname{final} \text { mult }}(2 S+$} & \multirow[b]{2}{*}{$\begin{array}{l}\text { deprot } \\
\text { species }\end{array}$} & \multicolumn{2}{|c|}{ Asp170 } & \multicolumn{2}{|c|}{ Glu354 } & \multicolumn{2}{|c|}{ Glu189 } & \multicolumn{2}{|c|}{ Glu333 } & \multicolumn{2}{|c|}{ Asp342 } & \multicolumn{2}{|c|}{ Ala344 } \\
\hline & & & & & sym & asym & sym & asym & sym & asym & sym & asym & sym & asym & sym & asym \\
\hline \multirow[t]{3}{*}{ A } & $+1 /+2$ & $3,4,4,3$ & 15 & & -7 & -3 & -48 & +3 & +3 & +1 & -3 & -30 & -8 & -55 & -12 & -13 \\
\hline & $+1 /+1$ & $3,4,4,3$ & 15 & O5 & +6 & -5 & -15 & -15 & +1 & +43 & +2 & -7 & -10 & -13 & +3 & -7 \\
\hline & $+1 /+1$ & $3,4,4,3$ & 15 & W2 & +24 & -7 & -31 & +6 & +2 & +12 & -2 & +4 & -7 & -35 & +3 & -5 \\
\hline \multirow[t]{5}{*}{ B } & $0 / 0$ & $3,3,4,3$ & 16 & O5 & -25 & +6 & -22 & -14 & -25 & +77 & +1 & -4 & -3 & -2 & -12 & -18 \\
\hline & $0 / 0$ & $3,3,4,4$ & 15 & W1, O5 & +4 & -4 & -27 & -46 & +5 & +17 & 0 & +4 & -7 & +10 & 0 & 0 \\
\hline & $+1 /+2$ & $3,4,4,3$ & 15 & & -41 & -7 & -44 & -22 & +15 & -16 & -12 & -39 & -5 & -29 & -19 & -7 \\
\hline & $+1 /+1$ & $3,4,4,3$ & 15 & O3 & -9 & -6 & -42 & -3 & +15 & -5 & -9 & -24 & -3 & -6 & +22 & -12 \\
\hline & $+1 /+1$ & $3,4,4,3$ & 15 & O5 & -36 & -2 & -27 & -36 & -22 & +72 & -2 & -10 & -11 & +7 & -36 & -7 \\
\hline \multirow[t]{3}{*}{$\mathrm{C}$} & $0 / 0$ & $3,4,4,3$ & 15 & O5 & +15 & +41 & -8 & -38 & +15 & -40 & -6 & +4 & -9 & +4 & -7 & -2 \\
\hline & $0 / 0$ & $3,4,4,3$ & 15 & W2 & +2 & +27 & -4 & -28 & -1 & +8 & +1 & -17 & -5 & +6 & -9 & 0 \\
\hline & $0 /+1$ & $3,4,4,3$ & 15 & & +2 & -2 & -13 & -45 & 0 & -9 & 0 & -31 & -4 & -8 & -19 & -11 \\
\hline
\end{tabular}

Table 5. Frequency Changes Associated with Oxidation of Mn4

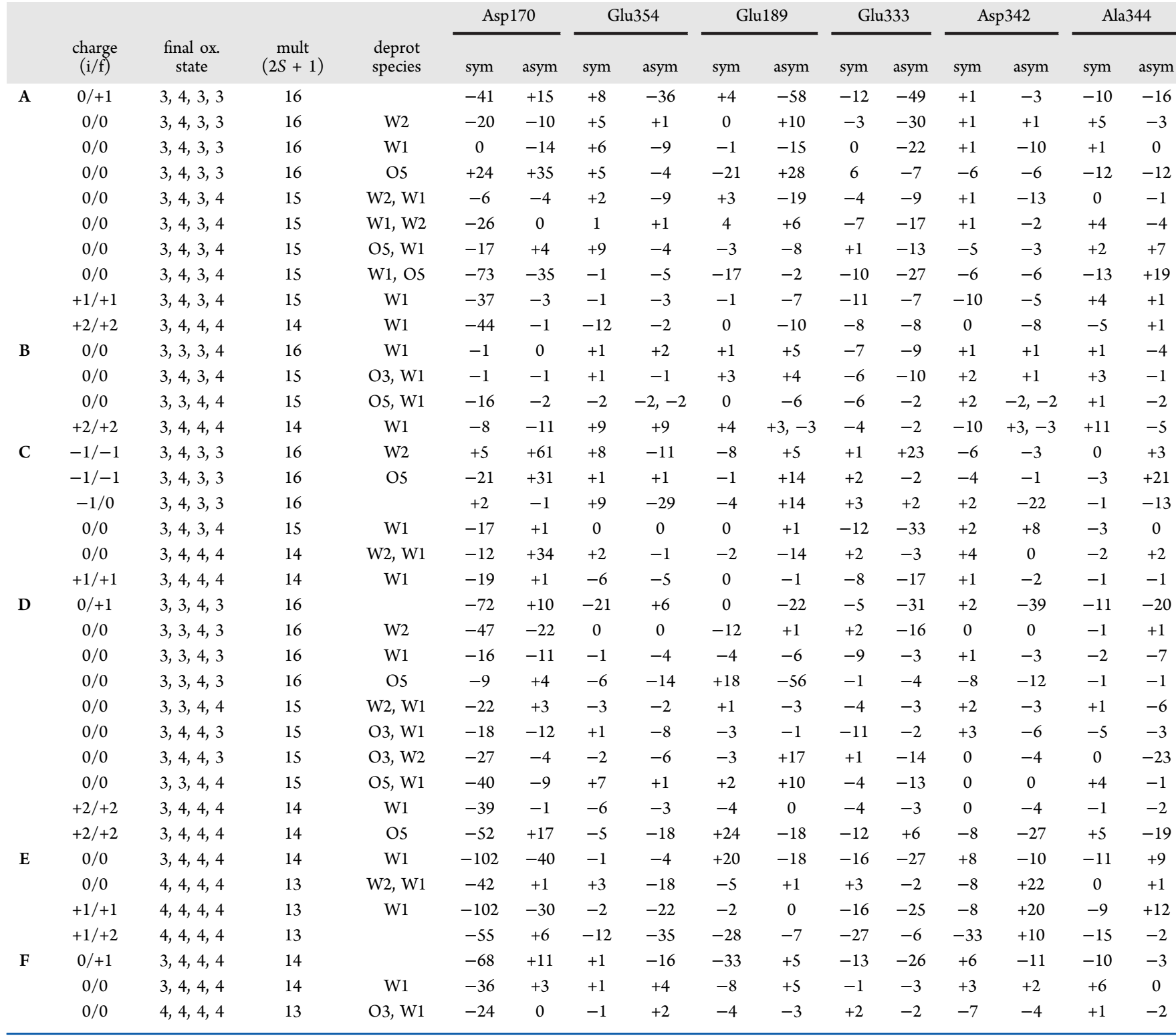

The charge column describes the initial and final charge of the clusters; oxidation with deprotonation of a water or hydroxyl ligand conserves the charge, while direct oxidation increases the positive charge on the cluster. The multiplicity is tied to the oxidation state of the cluster since each $\mathrm{Mn}$ center is assumed to be high spin. The oxidation state is written in the order of Mn1, Mn2, Mn3, Mn4. Some carboxylate stretching modes are strongly coupled to each other and cannot be resolved by 
inspection, so these ligands would appear to have two frequencies for some vibrational mode. The shifts of these coupled modes are separated by a comma in the tables. The species deprotonated in each step is shown in brackets, in the order in which the deprotonations were undertaken.

Mn1 oxidation (Table 2) causes large, widespread shifts in all clusters. The shift of the Glu189 symmetric mode roughly decreases by a factor of 3 with $\mathrm{O} 3$ deprotonation in $\mathbf{B}$ and $\mathbf{D}$. No corresponding decrease in frequency shifts was observed with other deprotonations, however.

Mn2 oxidation (Table 3) has only been observed in clusters $\mathbf{B}$ and $\mathbf{D}$. In cluster $\mathbf{B}, \mathrm{Mn} 2$ oxidation downshifts the symmetric stretch of Ala344, and mildly downshifts the asymmetric stretches of Glu354, Glu333, and Asp342; O3 deprotonation suppresses these shifts, and decreases the maximum shift at Ala344 from -51 to $-12 \mathrm{~cm}^{-1}$. In $\mathbf{D}$, oxidation with $\mathrm{O} 3$ deprotonation suppresses shifts relative to direct oxidation, whereas W2 and O5 deprotonations do not suppress shifts.

Mn3 oxidation (Table 4) also causes widespread frequency shifts which are not strongly affected by deprotonation. O5 deprotonation in $\mathbf{A}$ reduces the shifts somewhat relative to direct oxidation, but does not have a clear-cut effect on the shifts of $\mathbf{B}$ or $\mathbf{C}$.

Mn4 is the most frequently oxidized manganese center in this study (Table 5). Direct oxidation of Mn4 without deprotonation results in widespread shifts similar to those observed in the oxidation of Mn1 and Mn3. With deprotonation of $\mathrm{W} 2$ or $\mathrm{W} 1$, however, the shifts are significantly decreased in all clusters except E. A comparison between (O5, W1) and (W2, W1) in A, B, and D demonstrates that larger shifts occur if $\mathrm{O} 5$ is deprotonated, as (W2, W1) has smaller shifts than (O5, W1) in these clusters. A and $\mathbf{B}$ which have $\mathrm{O} 5$ as $\mathrm{H}_{2} \mathrm{O}$ generally display smaller shifts than the other clusters in this study, especially when they are neutrally charged.

We also observed that frequency shift suppresion via W2 or W1 deprotonation is most effective when the charge of the cluster is zero. $\mathbf{C}$ is negatively charged in its lowest oxidation state, and has smaller shifts without deprotonation of W2 when oxidized in that negatively charged state, while the shifts in other clusters progressively increase as the charge increases (from neutral charge). The protonation state of W2 also appears to have an effect, as $\mathbf{B}$ and $\mathbf{F}$ show smaller frequency shifts than their tautomers $\mathbf{A}$ and $\mathbf{E}$, respectively, following deprotonation.

\section{DISCUSSION AND CONCLUSION}

Deprotonation of $\mathrm{O} 3$ and terminal waters on $\mathrm{Mn} 4$ suppresses frequency shifts caused by oxidation, as shown in Figures 4 and 5 , provided that the deprotonated species is directly ligated to the oxidized manganese center. Deprotonation also curbs frequency shifts in ligands not directly ligated to the metal center oxidized. For example, in $\mathrm{D}$, the direct oxidation of $\mathrm{Mn} 4$ caused pervasive frequency shifts, consistent with a change in the conformation of the cluster; the oxidation of $\mathrm{Mn} 4$ with deprotonation of W1 or W2, however, suppresses these shifts, leaving only a moderate shift in the Asp170 frequencies. Thus, deprotonation also serves to minimize conformational changes within the cluster. The deprotonation of O5, however, does not reduce shifts and appears to cause additional frequency shifts on its own. This can be attributed to the conformational changes that follow a change in the protonation state of $\mathrm{O}$, which is unsurprising as $\mathrm{O} 5$ occupies a central position in these clusters.

The factors responsible for variances in the efficacy of frequency shift suppression in these clusters appear to be the $\mathrm{Mn}-\mathrm{O} 5$ distances, the charge of the cluster, and the protonation state of W2. A and $\mathbf{B}$ have long $\mathrm{Mn}-\mathrm{O} 5$ distances owing to $\mathrm{O} 5$ being fully protonated, and display very small frequency shifts when oxidized with deprotonation in their neutral states. We observed a reduction in the frequency suppression effect as the clusters take on shorter $\mathrm{Mn}-\mathrm{O} 5$ distances (due to $\mathrm{O} 5$ being $\mathrm{OH}$ or $\mathrm{O}$ ) or deviate from neutral charge (i.e., $\mathbf{C}$, and all clusters in positively charged states). Frequency shift suppression via deprotonation is also more effective when $\mathrm{W} 2$ is $\mathrm{OH}$, since $\mathbf{B}$ and $\mathbf{F}$ display smaller shifts than $\mathbf{A}$ and $\mathbf{E}$, respectively, following deprotonation; $\mathbf{A}$ and $\mathbf{E}$ also display smaller shifts after W2 is deprotonated [see (W2, $\mathrm{W} 1$ ) in Table 5]. The reason W2 protonation has such an effect is as yet unclear.

In $\mathbf{B}$, the shifts are usually less than $10 \mathrm{~cm}^{-1}$ when deprotonation has occurred at the center of oxidation (e.g., $\mathrm{O} 3$ deprotonation when $\mathrm{Mn} 2$ is oxidized, and W1 deprotonation when Mn4 is oxidized); the largest shifts were only 12 $\mathrm{cm}^{-1}$ at Glu354 and Ala344 with O3 deprotonation. If we take the frequency shifts of our gas phase clusters to be representative of what might be expected in PSII, then these shifts are small enough that they may be obscured by the minor changes that occur in the protein backbone due to ligand mutation. The Mn4 oxidation-induced shifts at Asp170, in particular, are almost completely nullified by W1 deprotonation. This result indicates that any oxidation-driven frequency shift in Asp170 carboxylate modes would be very difficult to observe in midfrequency FTIR difference spectra, which would explain the experimental results obtained from Asp170 mutants. $^{41}$

It is also known that no deprotonation occurs in the $S_{1} / S_{2}$ transition, ${ }^{42-44}$ and a $17-36 \mathrm{~cm}^{-1}$ downshift has been experimentally assigned to the symmetric mode of the D1 protein $\mathrm{C}$-terminus in that transition, with that mode being at $\sim 1356 \mathrm{~cm}^{-1}$ in the $S_{1}$ state. ${ }^{11,45}$ The calculated frequency of the corresponding ligand in the nominal $S_{1}$ state of $\mathbf{B}$ has a frequency of $1389 \mathrm{~cm}^{-1}$, and it is shifted by -51 and $-12 \mathrm{~cm}^{-}$ when $\mathbf{B}$ is oxidized without deprotonation and with $\mathrm{O} 3$ deprotonation, respectively (see Table 3 for the shifts; absolute frequencies are available in the Supporting Information). The experimentally observed shifts appear to fit within that calculated range of frequency shifts $(17-36$ versus $12-51$ $\mathrm{cm}^{-1}$ ). It is also notable that the next largest symmetric mode shift in the direct oxidation of B was only $-11 \mathrm{~cm}^{-1}$ for Glu189, which is compatible with the difficulty in assigning FTIR difference features to other first-shell ligands in that transition experimentally.

Deprotonation coupled with oxidation generally reduces the oxidation energy, and maintains it to within $1 \mathrm{eV}$ for successive oxidations (see Figure 3), consistent with our previous findings and also experimental results obtained with synthetic manganese complexes. ${ }^{14,46,47}$ Oxidation with O5 deprotonation appears to be very thermodynamically favorable, and is slightly more so than oxidation with $\mathrm{W} 2$ or $\mathrm{W} 1$ deprotonation. However, it is important to note that the dielectric and conformational effects of protein ligation have not been accounted for in these gas phase calculations, which will affect these oxidation energy calculations. ${ }^{48,49}$ In particular, the hydrogen bond network that surrounds the WOC could favor 
the deprotonation of the terminal waters over the deprotonation of $\mathrm{O5}$, as $\mathrm{W} 1$ and $\mathrm{W} 2$ are directly linked to this network. ${ }^{8,9,11,50}$ Furthermore, a recent study by Saito and coworkers has shown that a corresponding hydrogen bond network is absent for $\mathrm{O} 5$ in the $\mathrm{S}_{1}$ state, which greatly increases the activation barrier for $\mathrm{O} 5$ deprotonation. ${ }^{51}$

In 2008, Sproviero and co-workers performed DFT-QM/ MM vibrational calculations on their model of the WOC, and found that carboxylate ligand frequencies were generally insensitive to manganese oxidation states, unless a carboxylate was ligated along the Jahn-Teller axis of a Mn(III) center. ${ }^{52}$ Our results are not consistent with those findings, as we found that large frequency shifts can be induced in equatorial carboxylate ligands; Berggren et al. also found that carboxylate stretching shifts are easily observed even in carboxylate ligands that do not ligate a Jahn-Teller axis, in synthetic manganese dimers. ${ }^{53}$ We conclude that the insensitivity of FTIR S-state difference spectra to carboxylate ligand mutation is due to water/hydroxyl ligand deprotonation at the metal center undergoing oxidation in the WOC, rather than an inherent insensitivity of carboxylate ligand stretching frequencies to manganese oxidation.

\section{ASSOCIATED CONTENT}

\section{S Supporting Information}

The Supporting Information is available free of charge on the ACS Publications website at DOI: 10.1021/acs.jpcb.5b09987.

Results of exploratory calculations on cluster $\mathbf{B}$, as well as details on the absolute energies in Hartrees, carboxylate stretching frequencies, $\mathrm{Mn}$ spin densities, and coordinates of the selected models (PDF)

\section{AUTHOR INFORMATION}

\section{Corresponding Authors}

*E-mail: wychuah@yahoo.com.

*E-mail: Rob.Stranger@anu.edu.au.

*E-mail: Ron.Pace@anu.edu.au.

*E-mail: krausz@rsc.anu.edu.au.

*E-mail: t.frankcombe@adfa.edu.au.

\section{Notes}

The authors declare no competing financial interest.

\section{ACKNOWLEDGMENTS}

We would like to acknowledge Richard Terrett for useful discussions. This work was supported by the NCI National Facility at the ANU, and we recognize the support of the Australian Research Council through Grant DP110104565.

\section{REFERENCES}

(1) Wydrzynski, T. J.; Satoh, K. Photosystem II: the Light-Driven Water: Plastoquinone Oxidoreductase; Springer Science \& Business Media, 2006; Vol. 22.

(2) Haumann, M.; Müller, C.; Liebisch, P.; Iuzzolino, L.; Dittmer, J.; Grabolle, M.; Neisius, T.; Meyer-Klaucke, W.; Dau, H. Structural and Oxidation State Changes of the Photosystem II Manganese Complex in Four Transitions of the Water Oxidation Cycle Characterized by Xray Absorption Spectroscopy at $20 \mathrm{~K}$ and Room Temperature. Biochemistry 2005, 44, 1894-1908.

(3) Messinger, J.; Robblee, J. H.; Bergmann, U.; Fernandez, C.; Glatzel, P.; Visser, H.; Cinco, R. M.; McFarlane, K. L.; Bellacchio, E.; Pizarro, S. A.; et al. Absence of Mn-Centered Oxidation in the $S_{2}$ to $S_{3}$ Transition: Implications for the Mechanism of Photosynthetic Water Oxidation. J. Am. Chem. Soc. 2001, 123, 7804-7820.
(4) Glatzel, P.; Schroeder, H.; Pushkar, Y.; Boron, T., III; Mukherjee, S.; Christou, G.; Pecoraro, V. L.; Messinger, J.; Yachandra, V. K.; Bergmann, U.; et al. Electronic Structural Changes of $\mathrm{Mn}$ in the Oxygen-Evolving Complex of Photosystem II During the Catalytic Cycle. Inorg. Chem. 2013, 52, 5642-5644.

(5) Messinger, J.; Nugent, J. H.; Evans, M. C. Detection of an EPR Multiline Signal for the $\mathrm{S}_{0}$ * State in Photosystem II. Biochemistry 1997, 36, 11055-11060.

(6) Boussac, A.; Sugiura, M.; Rutherford, A. W.; Dorlet, P. Complete EPR Spectrum of the $S_{3}$-State of the Oxygen-Evolving Photosystem II. J. Am. Chem. Soc. 2009, 131, 5050-5051.

(7) Krewald, V.; Retegan, M.; Cox, N.; Messinger, J.; Lubitz, W.; DeBeer, S.; Neese, F.; Pantazis, D. A. Metal Oxidation States in Biological Water Splitting. Nat. Chem. 2015, 6, 1676-1695.

(8) Kawakami, K.; Umena, Y.; Kamiya, N.; Shen, J.-R. Structure of the Catalytic, Inorganic Core of Oxygen-Evolving Photosystem II at 1.9 Å Resolution. J. Photochem. Photobiol., B 2011, 104, 9-18.

(9) Umena, Y.; Kawakami, K.; Shen, J.-R; Kamiya, N. Crystal Structure of Oxygen-Evolving Photosystem II at a Resolution of $1.9 \AA$. Nature 2011, 473, 55-61.

(10) Suga, M.; Akita, F.; Hirata, K.; Ueno, G.; Murakami, H.; Nakajima, Y.; Shimizu, T.; Yamashita, K.; Yamamoto, M.; Ago, H.; et al. Native Structure of Photosystem II at 1.95 A Resolution Viewed by Femtosecond X-ray Pulses. Nature 2014, 517, 99-103.

(11) Debus, R. J. FTIR Studies of Metal Ligands, Networks of Hydrogen Bonds, and Water Molecules Near the Active Site $\mathrm{Mn}_{4} \mathrm{CaO}_{5}$ Cluster in Photosystem II. Biochim. Biophys. Acta, Bioenerg. 2015, 1847, 19-34.

(12) Chu, H.-A.; Debus, R. J.; Babcock, G. T. D1-Asp170 is Structurally-Coupled to the Oxygen-Evolving Complex in Photosystem II as Revealed by Light-Induced Fourier Transform Infrared Difference Spectroscopy. Biochemistry 2001, 40, 2312-2316.

(13) Kimura, Y.; Mizusawa, N.; Ishii, A.; Nakazawa, S.; Ono, T.-a. Changes in Structural and Functional Properties of Oxygen-Evolving Complex Induced by Replacement of D1-Glutamate 189 with Glutamine in Photosystem II: Ligation of Glutamate 189 Carboxylate to the Manganese Cluster. J. Biol. Chem. 2005, 280, 37895-37900.

(14) Chuah, W. Y.; Stranger, R.; Pace, R. J.; Krausz, E.; Frankcombe, T. J. Ab Initio Modeling of the Effect of Oxidation Coupled with $\mathrm{H}_{\mathrm{n}} \mathrm{O}$ Deprotonation on Carboxylate Ligands in $\mathrm{Mn} / \mathrm{Ca}$ Clusters. J. Phys. Chem. B 2014, 118, 3553-3558.

(15) Terrett, R.; Frankcombe, T.; Pace, R.; Stranger, R. Effect of Concomitant Oxidation and Deprotonation of Hydrated Mn Centres in Rationalising the FTIR Difference Silence of D1-Asp170 in Photosystem II. J. Inorg. Biochem. 2016, 155, 101-104.

(16) Eilers, G.; Zettersten, C.; Nyholm, L.; Hammarström, L.; Lomoth, R. Ligand Exchange Upon Oxidation of a Dinuclear Mn Complex-Detection of Structural Changes by FT-IR Spectroscopy and ESI-MS. Dalton Trans. 2005, 1033-1041.

(17) Terrett, R.; Petrie, S.; Pace, R. J.; Stranger, R. What Does the SrSubstituted 2.1 A Resolution Crystal Structure of Photosystem II Reveal about the Water Oxidation Mechanism? Chem. Commun. 2014, 50, 3187-3190.

(18) Luber, S.; Rivalta, I.; Umena, Y.; Kawakami, K.; Shen, J.-R.; Kamiya, N.; Brudvig, G. W.; Batista, V. S. $\mathrm{S}_{1}$-State Model of the $\mathrm{O}_{2}$ Evolving Complex of Photosystem II. Biochemistry 2011, 50, 63086311.

(19) Ames, W.; Pantazis, D. A.; Krewald, V.; Cox, N.; Messinger, J.; Lubitz, W.; Neese, F. Theoretical Evaluation of Structural Models of the $\mathrm{S}_{2}$-State in the Oxygen-Evolving Complex of Photosystem II: Protonation States and Magnetic Interactions. J. Am. Chem. Soc. 2011, 133, 19743-19757.

(20) Kolling, D. R.; Cox, N.; Ananyev, G. M.; Pace, R. J.; Dismukes, G. C. What are the Oxidation States of Manganese Required to Catalyze Photosynthetic Water Oxidation? Biophys. J. 2012, 103, 313322.

(21) Gatt, P.; Petrie, S.; Stranger, R.; Pace, R. J. Rationalizing the 1.9 A Crystal Structure of Photosystem II: A Remarkable Jahn-Teller 
Balancing Act Induced by a Single Proton Transfer. Angew. Chem. 2012, 124, 12191-12194.

(22) Pace, R. J.; Stranger, R.; Petrie, S. Why Nature Chose Mn for the Water Oxidase in Photosystem II. Dalton T. 2012, 41, 7179-7189.

(23) Siegbahn, P. E. Water Oxidation Mechanism in Photosystem II, Including Oxidations, Proton Release Pathways, O-O Bond Formation and $\mathrm{O}_{2}$ Release. Biochim. Biophys. Acta, Bioenerg. 2013, 1827, 10031019.

(24) Cox, N.; Pantazis, D. A.; Neese, F.; Lubitz, W. Biological Water Oxidation. Acc. Chem. Res. 2013, 46, 1588-1596.

(25) Petrie, S.; Stranger, R.; Pace, R. J. Rationalising the Geometric Variation Between the A and B Monomers in the $1.9 \AA$ Crystal Structure of Photosystem II. Chem. - Eur. J. 2015, 21, 6780-6792.

(26) Petrie, S.; Gatt, P.; Jin, L.; Stranger, R.; Pace, R. J. On the Nature of the $S_{0}, S_{1}$ and $S_{2}$ States in the Oxygen-Evolving Centre of Photosystem II. Angew. Chem., Int. Ed. 2015, in press.

(27) Li, X.; Siegbahn, P. E. Alternative Mechanisms for $\mathrm{O}_{2}$ Release and $\mathrm{O}-\mathrm{O}$ Bond Formation in the Oxygen-Evolving Complex of Photosystem II. Phys. Chem. Chem. Phys. 2015, 17, 12168-12174.

(28) Cox, N.; Retegan, M.; Neese, F.; Pantazis, D. A.; Boussac, A.; Lubitz, W. Electronic Structure of the Oxygen-Evolving Complex in Photosystem II Prior to O-O Bond Formation. Science 2014, 345, 804-808.

(29) Kurashige, Y.; Chan, G. K.-L.; Yanai, T. Entangled Quantum Electronic Wavefunctions of the $\mathrm{Mn}_{4} \mathrm{CaO}_{5}$ Cluster in Photosystem II. Nat. Chem. 2013, 5, 660-666.

(30) Pace, R. J.; Jin, L.; Stranger, R. What Spectroscopy Reveals Concerning the Mn Oxidation Levels in the Oxygen-Evolving Complex of Photosystem II: X-ray to Near Infra-Red. Dalton T. 2012, 41, 11145-11160.

(31) Jin, L.; Smith, P.; Noble, C. J.; Stranger, R.; Hanson, G. R.; Pace, R. J. Electronic Structure of the Oxygen-Evolving Complex in Photosystem II, as Revealed by 55-Mn Davies ENDOR Studies at 2.5 K. Phys. Chem. Chem. Phys. 2014, 16, 7799-7812.

(32) Frisch, M. J.; Trucks, G. W.; Schlegel, H. B.; Scuseria, G. E.; Robb, M. A.; Cheeseman, J. R.; Scalmani, G.; Barone, V.; Mennucci, B.; Petersson, G. A.; et al. Gaussian 09 Revision D.01; Gaussian Inc.: Wallingford, CT, 2009.

(33) Alecu, I.; Zheng, J.; Zhao, Y.; Truhlar, D. G. Computational Thermochemistry: Scale Factor Databases and Scale Factors for Vibrational Frequencies Obtained from Electronic Model Chemistries. J. Chem. Theory Comput. 2010, 6, 2872-2887.

(34) Shoji, M.; Isobe, H.; Yamanaka, S.; Suga, M.; Akita, F.; Shen, J.R.; Yamaguchi, K. On the Guiding Principles for Lucid Understanding of the Damage-Free $\mathrm{S}_{1}$ Structure of the $\mathrm{CaMn}_{4} \mathrm{O}_{5}$ Cluster in the Oxygen-Evolving Complex of Photosystem II. Chem. Phys. Lett. 2015, $627,44-52$.

(35) Shoji, M.; Isobe, H.; Yamanaka, S.; Umena, Y.; Kawakami, K.; Kamiya, N.; Shen, J.-R.; Yamaguchi, K. Theoretical Insight in to Hydrogen-Bonding Networks and Proton Wire for the $\mathrm{CaMn}_{4} \mathrm{O}_{5}$ Cluster of Photosystem II. Elongation of $\mathrm{Mn}-\mathrm{Mn}$ Distances with Hydrogen Bonds. Catal. Sci. Technol. 2013, 3, 1831-1848.

(36) Amin, M.; Vogt, L.; Szejgis, W.; Vassiliev, S.; Brudvig, G. W.; Bruce, D.; Gunner, M. R. Proton-Coupled Electron Transfer During the S-State Transitions of the Oxygen-Evolving Complex of Photosystem II. J. Phys. Chem. B 2015, 119, 7366-7377.

(37) Pantazis, D. A.; Ames, W.; Cox, N.; Lubitz, W.; Neese, F. Two Interconvertible Structures that Explain the Spectroscopic Properties of the Oxygen-Evolving Complex of Photosystem II in the $\mathrm{S}_{2}$ State. Angew. Chem., Int. Ed. 2012, 51, 9935-9940.

(38) Barber, J.; Archer, M. P680, the Primary Electron Donor of Photosystem II. J. Photochem. Photobiol., A 2001, 142, 97-106.

(39) Hasegawa, K.; Noguchi, T. Density Functional Theory Calculations on the Dielectric Constant Dependence of the Oxidation Potential of Chlorophyll: Implication for the High Potential of P680 in Photosystem II. Biochemistry 2005, 44, 8865-8872.

(40) Takahashi, R.; Hasegawa, K.; Noguchi, T. Effect of Charge Distribution over a Chlorophyll Dimer on the Redox Potential of P680 in Photosystem II as Studied by Density Functional Theory Calculations. Biochemistry 2008, 47, 6289-6291.

(41) Debus, R. J.; Strickler, M. A.; Walker, L. M.; Hillier, W. No evidence from FTIR Difference Spectroscopy that Aspartate-170 of the D1 Polypeptide Ligates a Manganese Ion that Undergoes Oxidation During the $S_{0}$ to $S_{1}, S_{1}$ to $S_{2}$, or $S_{2}$ to $S_{3}$ Transitions in Photosystem II. Biochemistry 2005, 44, 1367-1374.

(42) Fowler, C. F. Proton Evolution from Photosystem II: Stoichiometry and Mechanistic Considerations. Biochim. Biophys. Acta, Bioenerg. 1977, 462, 414-421.

(43) Schlodder, E.; Witt, H. T. Stoichiometry of Proton Release from the Catalytic Center in Photosynthetic Water Oxidation: ReExamination by a Glass Electrode Study at $\mathrm{pH}$ 5.5-7.2. J. Biol. Chem. 1999, 274, 30387-30392.

(44) Suzuki, H.; Sugiura, M.; Noguchi, T. Monitoring Proton Release During Photosynthetic Water Oxidation in Photosystem II by means of Isotope-Edited Infrared Spectroscopy. J. Am. Chem. Soc. 2009, 131, $7849-7857$.

(45) Chu, H.-A.; Hillier, W.; Debus, R. J. Evidence that the Cterminus of the D1 Polypeptide of Photosystem II is Ligated to the Manganese Ion that Undergoes Oxidation During the $S_{1}$ to $S_{2}$ Transition: An Isotope-Edited FTIR Study. Biochemistry 2004, 43, $3152-3166$

(46) Thorp, H. H.; Sarneski, J. E.; Brudvig, G. W.; Crabtree, R. H. Proton-Coupled Electron Transfer in Manganese Complex $\left[(\text { bpy })_{2} \mathrm{Mn}(\mathrm{O})_{2} \mathrm{Mn}(\mathrm{bpy})_{2}\right]^{3+}$. J. Am. Chem. Soc. 1989, 111, 92499250.

(47) Baldwin, M. J.; Pecoraro, V. L. Energetics of Proton-Coupled Electron Transfer in High-Valent $\mathrm{Mn}_{2}(\mu \text {-O })_{2}$ Systems: Models for Water Oxidation by the Oxygen-Evolving Complex of Photosystem II. J. Am. Chem. Soc. 1996, 118, 11325-11326.

(48) Formaneck, M. S.; Li, G.; Zhang, X.; Cui, Q. Calculating Accurate Redox Potentials in Enzymes with a Combined QM/MM Free Energy Perturbation Approach. J. Theor. Comput. Chem. 2002, 1, $53-67$.

(49) Mahboob, A.; Vassiliev, S.; Poddutoori, P. K.; van der Est, A.; Bruce, D. Factors Controlling the Redox Potential of $\mathrm{ZnCe}_{6}$ in an Engineered Bacterioferritin Photochemical 'Reaction Centre'. PLoS One 2013, 8, e68421.

(50) Service, R. J.; Hillier, W.; Debus, R. J. Network of Hydrogen Bonds near the Oxygen-Evolving $\mathrm{Mn}_{4} \mathrm{CaO}_{5}$ Cluster of Photosystem II Probed with FTIR Difference Spectroscopy. Biochemistry 2014, 53, 1001-1017.

(51) Saito, K.; Rutherford, A. W.; Ishikita, H. Energetics of Proton Release on the First Oxidation Step in the Water-Oxidizing Enzyme. Nat. Commun. 2015, 6, 8488.

(52) Sproviero, E. M.; Gascón, J. A.; McEvoy, J. P.; Brudvig, G. W.; Batista, V. S. Quantum Mechanics/Molecular Mechanics Study of the Catalytic Cycle of Water Splitting in Photosystem II. J. Am. Chem. Soc. 2008, 130, 3428-3442.

(53) Berggren, G.; Anderlund, M. F.; Styring, S.; Thapper, A. FTIR Study of Manganese Dimers with Carboxylate Donors as Model Complexes for the Water Oxidation Complex in Photosystem II. Inorg. Chem. 2012, 51, 2332-2337. 